\title{
Growth and photoluminescence studies of Zn-doped AIN epilayers
}

\author{
N. Nepal, M. L. Nakarmi, H. U. Jang, J. Y. Lin, and H. X. Jiang ${ }^{a}$ \\ Department of Physics, Kansas State University, Manhattan, Kansas 66506
}

(Received 31 July 2006; accepted 4 October 2006; published online 10 November 2006)

\begin{abstract}
Deep ultraviolet time-resolved photoluminescence (PL) spectroscopy has been employed to study $\mathrm{Zn}$-doped AlN epilayers grown by metal-organic chemical vapor deposition. The PL spectra of Zn-doped AlN epilayer exhibited two impurity emission lines at 5.40 and $4.50 \mathrm{eV}$, which were absent in undoped epilayers and assigned to the transitions of free electrons and electrons bound to nitrogen vacancies with three positive charges $(0.90 \mathrm{eV}$ deep $)$ to the $\mathrm{Zn}^{0}$ acceptors. By comparing PL spectra of $\mathrm{Zn}$ - and Mg-doped AlN epilayers with undoped epilayers, it was deduced that $\mathrm{Zn}$ energy level is about $0.74 \mathrm{eV}$, which is about $0.23 \mathrm{eV}$ deeper than the $\mathrm{Mg}$ energy level $(0.51 \mathrm{eV})$ in AlN. It is thus concluded that contrary to theoretical prediction, Zn would not be a better candidate than $\mathrm{Mg}$ as an acceptor dopant in AlN. (C) 2006 American Institute of Physics.
\end{abstract}

[DOI: $10.1063 / 1.2387869]$

AlN is emerging as an active semiconductor material due to the recent development of high quality AlN epilayer growth on sapphire, $\mathrm{SiC}$, and AlN bulk substrates. Because of its large direct band gap $(\sim 6.1 \mathrm{eV})$, AlN can be used for the development of optoelectronic devices operating from 200 to $350 \mathrm{~nm}$ by alloying with GaN. A recent demonstration of an AlN light emitting diode with emission wavelength at $210 \mathrm{~nm}$ has shown its high potential for obtaining optoelectronic devices active in the ultraviolet $C$-band (UVC) spectral range. ${ }^{1}$ Potential applications of compact light sources and detectors operating in the UVC spectral region range from sterilization, bioagent detection, and acoustic sound wave devices, to $\mathrm{x}$-ray detectors. ${ }^{2-5}$

For the applications of AlN as an active material, conductive $n$ - and $p$-type materials are required. While $n$-type AlN epilayers with reasonable conductivities have been achieved by Si doping, ${ }^{6-9} p$-type conductivity is extremely difficult to obtain due to the large activation energy of $\mathrm{Mg}$ acceptors. GaN with $p$-type conductivity can be reproducibly grown by metal-organic chemical vapor deposition (MOCVD) by $\mathrm{Mg}$ doping and subsequent annealing. ${ }^{10}$ The activation energy of $\mathrm{Mg}$ is about $160 \mathrm{meV}$ in $\mathrm{GaN}$, increases with $\mathrm{Al}$ content in $\mathrm{AlGaN}$ alloys, and is about $0.51 \mathrm{eV}$ in AlN. ${ }^{11-14} \mathrm{Zn}$ elements have been previously utilized as $p$-type dopants in $\mathrm{GaN},{ }^{15}$ which, however, rendered semiinsulating materials. The binding energy of $\mathrm{Zn}$ in $\mathrm{GaN}$ is about $0.34 \mathrm{eV}$, as determined by optical measurements. ${ }^{15-17}$ A previous calculation predicted that $\mathrm{Zn}$ occupies $\mathrm{Al}$ site in $\mathrm{AlN}$ and the activation energy of $\mathrm{Zn}$ acceptor in $\mathrm{AlN}$ is in the range of $0.22-0.44 \mathrm{eV},{ }^{18}$ which is significantly smaller than that of $\mathrm{Mg}$ in AlN. Since the free hole concentration increases exponentially with a decrease of the acceptor activation energy, any strategies that have the potential to reduce the activation energies of acceptors in AlN are worth pursuing. In this letter, we report on the growth and photoluminescence (PL) studies of Zn-doped AlN epilayers.

Zn-doped AlN epilayers of thickness $\sim 1 \mu \mathrm{m}$ were grown by MOCVD. Prior to the growth of Zn-doped layer, a $0.5 \mu \mathrm{m}$ thick undoped AlN epilayer was first grown on sapphire substrate as a template and was then followed by the

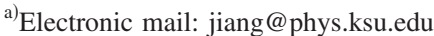

growth of Zn-doped AlN. Trimethyl aluminum and blue ammonia were used as aluminum and nitrogen sources, respectively. Dimethyl zinc was used as $\mathrm{Zn}$ source. The Zn dopant concentration was on the order of $10^{20} \mathrm{~cm}^{-3}$ as determined by secondary ion mass spectrometry measurement. The growth temperature and pressure were $1200{ }^{\circ} \mathrm{C}$ and 40 torr, respectively. Hall-effect measurements were attempted to measure the conductivity of $\mathrm{Zn}$-doped AlN epilayers. However, as-grown epilayers were highly resistive. Furthermore, subsequent postgrowth annealing of $\mathrm{Zn}$-doped AlN in nitrogen ambient did not result in $p$-type conduction. Deep UV PL spectroscopy ${ }^{19}$ was employed to study the optical properties of Zn-doped AlN.

Low temperature $(10 \mathrm{~K})$ PL spectra of $\mathrm{Zn}$ - and $\mathrm{Mg}$ doped AlN and undoped AlN epilayers are shown in Fig. 1. The PL spectrum of undoped AlN exhibits a strong band edge emission at $6.06 \mathrm{eV}$ due to the free exciton ${ }^{20}$ (FX) transition and virtually no impurity transitions. Since FX binding energy in AlN is around $0.08 \mathrm{eV},{ }^{21,22}$ the band gap of AlN at $10 \mathrm{~K}$ is thus around $6.14 \mathrm{eV}(\approx 6.06 \mathrm{eV}+0.08 \mathrm{eV})$. The

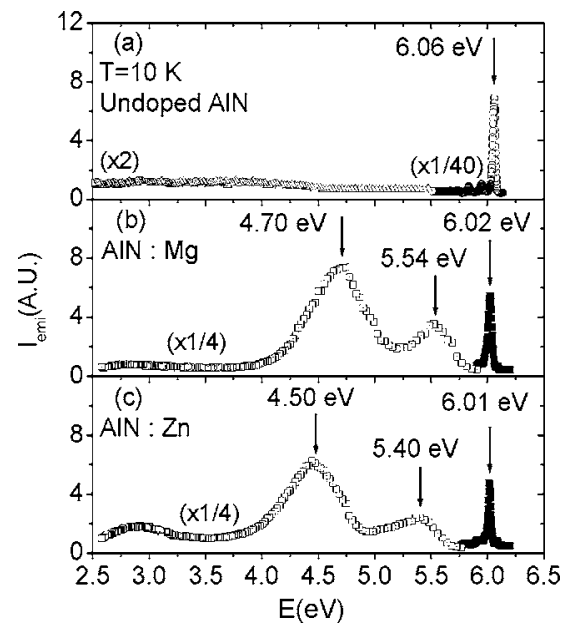

FIG. 1. PL spectra of (a) undoped, (b) Mg-doped, and (c) Zn-doped AlN epilayers measured at $10 \mathrm{~K}$. For the $\mathrm{Mg}$-(Zn-) doped AlN epilayers, the band edge transition at $6.06 \mathrm{eV}$ disappears and a new band edge emission line is observed at $6.02(6.01) \mathrm{eV}$. Additional impurity emission lines observed in $\mathrm{Mg}-(\mathrm{Zn}-)$ doped AlN at 4.70 (4.50) and 5.54 (5.40) eV are related with $\mathrm{Mg}(\mathrm{Zn})$ acceptor impurities. 


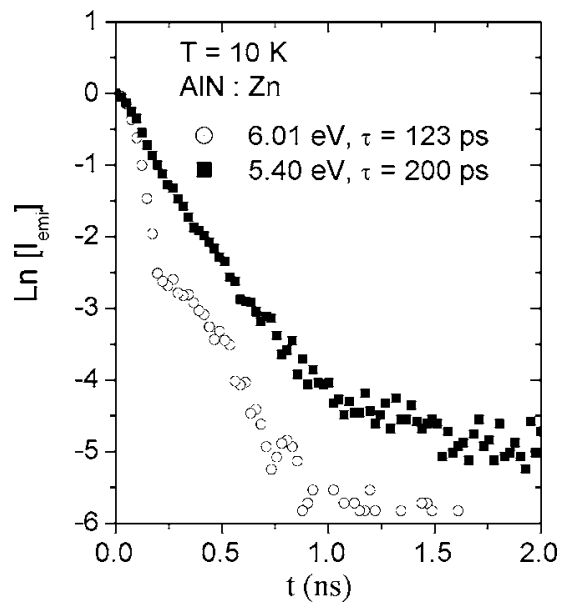

FIG. 2. Temporal responses of the $I_{1}$ and $5.40 \mathrm{eV}$ emission lines in $\mathrm{Zn}$ doped AlN epilayers measured at $10 \mathrm{~K}$.

PL spectrum of Mg-doped AlN comprises a band edge transition at $6.02 \mathrm{eV}$ due to the recombination of excitons bound to neutral $\mathrm{Mg}$ acceptors ( $I_{1}$ transition). Two additional impurity emission lines at 4.70 and $5.54 \mathrm{eV}$ in Mg-doped AlN are also observable and believed to be donor-acceptor-pair (DAP) transitions involving two different donors (deep and shallow level donors) and $\mathrm{Mg}$ acceptor. ${ }^{14}$ The deep level donors participated in the $4.70 \mathrm{eV}$ transition in $\mathrm{Mg}$-doped AlN were identified as nitrogen vacancies with three positive charges $\left(V_{N}^{3+}\right)$ that act as compensating centers for $p$-type doping. ${ }^{23}$

Compared to the PL spectrum of Mg-doped AlN, the PL spectrum of Zn-doped AlN has a very similar line shape, however, with the two impurity transitions redshifted to 4.50 and $5.40 \mathrm{eV}$ (with respect to 4.70 and $5.54 \mathrm{eV}$ in $\mathrm{Mg}$-doped AlN). The band edge emission line at $6.01 \mathrm{eV}$ in $\mathrm{Zn}$-doped AlN can be indisputably assigned to the recombination of excitons bound to neutral $\mathrm{Zn}$ acceptors ( $I_{1}$ transition). The measured recombination lifetime of the $4.50 \mathrm{eV}$ emission line is rather long $(\sim 1 \mu \mathrm{s})$ and is comparable to that of the $4.70 \mathrm{eV}$ line in Mg-doped AlN. Based on the assignment of the $4.70 \mathrm{eV}$ emission line in Mg-doped AlN, we assign the emission line at $4.50 \mathrm{eV}$ in $\mathrm{Zn}$-doped AlN to a DAP transition of electrons bounded to nitrogen vacancies with three positive charges $\left(V_{N}^{3+}\right)$ to neutral $\mathrm{Zn}$ acceptors, which is consistent with the measured long recombination lifetime. The width of the $V_{N}^{3+}$ related emission line is very broad, which is comparable to those of the cation vacancy $\left(V_{\text {cation }}\right)$ related emission lines in Si-doped AlN (Ref. 24) and is a typical characteristic of deep level impurity transitions. The binding energy of $V_{N}^{3+}$ in AlN has been calculated to be about $0.9 \mathrm{eV}, 5$ from which an energy level for $\mathrm{Zn}$ acceptors in AlN is thus deduced to be about $0.74 \mathrm{eV}$ $\left(E_{A} \approx 6.14 \mathrm{eV}-4.50 \mathrm{eV}-0.90 \mathrm{eV}=0.74 \mathrm{eV}\right)$ with neglecting Coulomb interactions between the ionized acceptors and donors.

Figure 2 shows the temporal responses of the $I_{1}$ transition at $6.01 \mathrm{eV}$ and the impurity transition at $5.40 \mathrm{eV}$ in Zn-doped AlN epilayer measured at $10 \mathrm{~K}$, which revealed a roughly single exponential decay kinetics with a decay time constant of about 123 ps for the $I_{1}$ transition and 200 ps for the $5.40 \mathrm{eV}$ impurity transition. The measured decay time constant of $I_{1}$ is comparable to a value of 130 ps observed in Mg-doped AlN. ${ }^{20}$ The recombination lifetime of 200 ps ob-

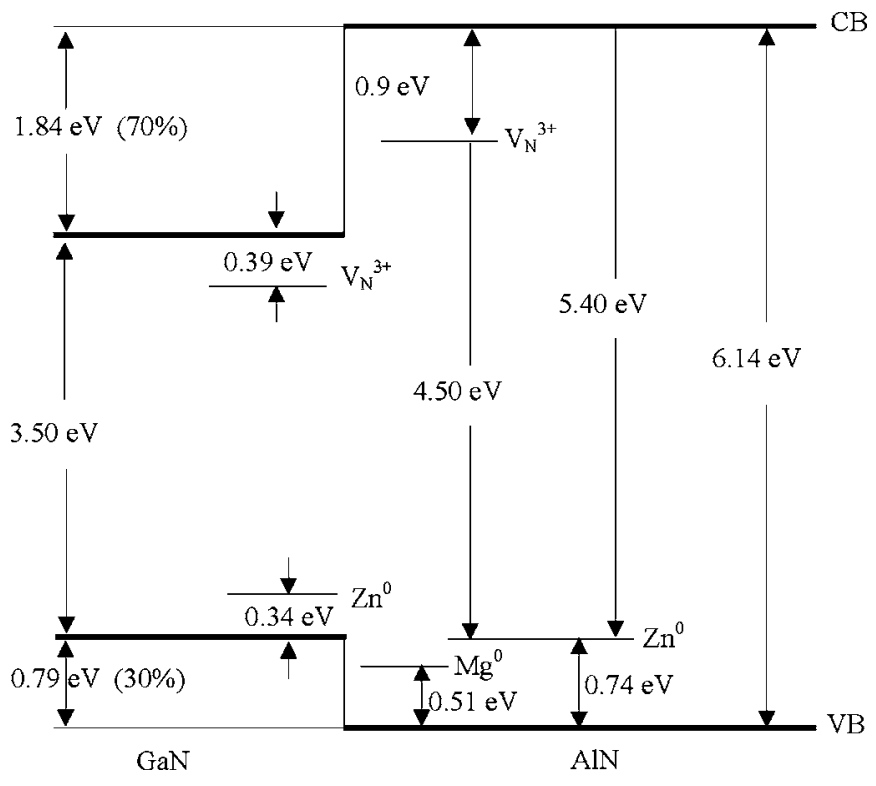

FIG. 3. Energy diagram showing the energy levels of $\mathrm{Mg}$ and $\mathrm{Zn}$ acceptors in AlN. Zn energy level in GaN is also included.

served for the $5.40 \mathrm{eV}$ emission line in $\mathrm{Zn}$-doped AlN is rather short, which seems to suggest that it is of a band-toimpurity type of transition. Based on this, we assign the $5.40 \mathrm{eV}$ emission peak to the transition of free electrons to neutral $\mathrm{Zn}$ acceptors $\left(\mathrm{Zn}^{0}\right)$, although a DAP type of transition involving a shallow donor and $\mathrm{Zn}^{0}$ cannot be totally precluded. This assignment provides an energy level of $\mathrm{Zn}$ acceptors in AlN to be $E_{A} \approx 6.14 \mathrm{eV}-5.40 \mathrm{eV}=0.74 \mathrm{eV}$, which agrees with the value deduced from the energy position of the $4.50 \mathrm{eV}$ emission line discussed above. It is worth noting that the identified origins of the two impurity transitions at 5.40 and $4.50 \mathrm{eV}$ in $\mathrm{Zn}$-doped AlN provide an identical activation energy of $0.74 \mathrm{eV}$ for $\mathrm{Zn}$ acceptors in AlN, which offers confidence in our assignments. Our results thus point to the fact that the energy level of $\mathrm{Zn}$ is about $0.23 \mathrm{eV}$ deeper than that of $\mathrm{Mg}$ in AlN $(0.51 \mathrm{eV})$. The energy levels related to $\mathrm{Zn}$ acceptors and corresponding transitions in AlN are shown in Fig. 3. Optically measured $\mathrm{Zn}$ level in $\mathrm{GaN}$ is also indicated in Fig. 3. ${ }^{15,16}$

To determine the binding energy of the $\mathrm{Zn}$ acceptor bound exciton in AlN, we have measured the temperature dependence of the $I_{1}$ emission intensity in $\mathrm{Zn}$-doped AlN and the result is shown in the inset of Fig. 4. The spectral peak position is redshifted with increasing temperature following the variation of the band gap. The thermal quenching of the $I_{1}$ transition is due to the dissociation of neutral acceptor bound excitons in Zn-doped AlN. Figure 4 shows the Arrhenius plot of the $I_{1}$ emission intensity in Zn-doped AlN. The solid line is the least-squares fit of the data with equation

$$
I_{\mathrm{emi}}=\frac{I_{0}}{1+c e^{\left(-E_{\mathrm{BX}} / K T\right)}},
$$

where $c$ is a constant and $E_{\mathrm{BX}}$ is the binding energy of neutral $\mathrm{Zn}$ acceptor bound excitons in AlN. The fitted value of $E_{\mathrm{BX}}$ is $50 \mathrm{meV}$ and is consistent with the value obtained from the difference between the spectral peak positions of FX in undoped AlN and $I_{1}$ in Zn-doped AlN epilayers $(6.06 \mathrm{eV}-6.01 \mathrm{eV}=0.05 \mathrm{eV})$. Experimentally measured binding energy of neutral $\mathrm{Mg}$ acceptor bound excitons in AIP license or copyright; see http://apl.aip.org/apl/copyright.jsp 


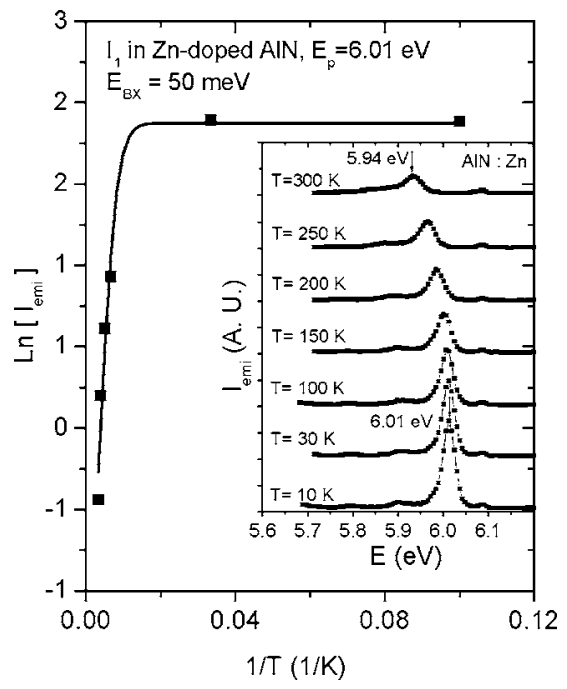

FIG. 4. Arrhenius plot of the integrated PL emission intensity of the $I_{1}$ emission peak in $\mathrm{Zn}$-doped AlN between 10 and $300 \mathrm{~K}$. The solid line is the least-squares fit of data with Eq. (1). The fitted value of the binding energy of neutral acceptor bound exciton $I_{1}\left(E_{\mathrm{BX}}\right)$ is also indicated. The inset is the temperature evolution of PL spectra of Zn-doped AlN epilayer measured from 10 to $300 \mathrm{~K}$.

AlN is about $0.04 \mathrm{eV} .{ }^{20}$ From Haynes' rule, ${ }^{26}$ the larger $E_{\mathrm{BX}}$ value in $\mathrm{Zn}$-doped AlN compared to that in Mg-doped AlN also hints a deeper energy level of $\mathrm{Zn}$ than $\mathrm{Mg}$ in AlN.

In summary, Zn-doped AlN epilayers were grown by MOCVD and their optical properties were probed by deep UV time-resolved PL. Zn related impurity transitions were observed at 5.40 and $4.50 \mathrm{eV}$ in $\mathrm{Zn}$-doped AlN, which are absent on undoped AlN layers. By comparing the PL spectra of $\mathrm{Zn}$ - and $\mathrm{Mg}$-doped and undoped AlN epilayers, the energy level of $\mathrm{Zn}$ acceptor in AlN was deduced to be about $0.74 \mathrm{eV}$, which is about $0.23 \mathrm{eV}$ deeper than the $\mathrm{Mg}$ level in AlN. Contrary to a previous theoretical prediction, our results thus suggest that $\mathrm{Zn}$ is not a better candidate than $\mathrm{Mg}$ as a $p$-type dopant in AIN. More theoretical and experimental investigations are required to further understand doping issues in AlN, particularly pertaining to $p$-type doping. Besides the search for suitable acceptor elements, innovative doping methods also need to be developed to bring a breakthrough in this field.
The authors would like to acknowledge supports provided by DOE (96ER45604) for this work.

${ }^{1}$ Y. Taniyasu, M. Kasu, and T. Makimoto, Nature (London) 441, 325 (2006).

${ }^{2}$ V. Adivarahan, S. Wu, J. P. Zhang, A. Chitnis, M. Shatalov, V. Mandavilli, R. Gaska, and M. Asif Khan, Appl. Phys. Lett. 84, 4762 (2004).

${ }^{3}$ H. Miyake, H. Yasukawa, Y. Kida, K. Ohta, Y. Shibata, A. Motogaito, K. Hiramatsu, Y. Ohuchi, K. Tadatomo, Y. Hamamura, and K. Fukui, Phys. Status Solidi A 200, 151 (2003).

${ }^{4}$ V. Mortet, O. Elmazria, M. Nesladek, M. B. Assouar, G. Vanhoyland, J. D'Haen, M. D'Olieslaeger, and P. Alnot, Appl. Phys. Lett. 81, 1720 (2002).

${ }^{5}$ A. T. Sowers, J. A. Christman, M. D. Bremser, B. L. Ward, R. F. Davis, and R. J. Nemanich, Appl. Phys. Lett. 71, 2289 (1997).

${ }^{6}$ Y. Taniyasu, M. Kasu, and N. Kobayashi, Appl. Phys. Lett. 81, 1255 (2002).

${ }^{7}$ M. L. Nakarmi, K. H. Kim, K. Zhu, J. Y. Lin, and H. X. Jiang, Appl. Phys. Lett. 85, 3769 (2004).

${ }^{8}$ Y. Taniyasu, M. Kasu, and T. Makimoto, Appl. Phys. Lett. 85, 4672 (2004).

${ }^{9}$ T. Ive, O. Brandt, H. Kostial, K. J. Friedland, L. Daweritz, and K. H. Ploog, Appl. Phys. Lett. 86, 024106 (2005).

${ }^{10}$ S. Nakamura, N. Iwasa, M. Senoh, and T. Mukai, Jpn. J. Appl. Phys., Part 1 31, 1258 (1992).

${ }^{11}$ R. J. Molnar and T. D. Moustakas, Bull. Am. Phys. Soc. 38, 445 (1993).

${ }^{12}$ T. Tanaka, A. Watanabe, A. Amano, Y. Kobayashi, I. Akasaki, S. Yamazaki, and M. Koike, Appl. Phys. Lett. 65, 593 (1994).

${ }^{13}$ J. Li, T. N. Oder, M. L. Nakarmi, J. Li, J. Y. Lin, and H. X. Jiang, Appl. Phys. Lett. 80, 1210 (2002).

${ }^{14}$ K. B. Nam, M. L. Nakarmi, J. Li, J. Y. Lin, and H. X. Jiang, Appl. Phys. Lett. 83, 878 (2003).

${ }^{15}$ M. Monemar, H. P. Gislason, and O. Lagerstedt, J. Appl. Phys. 51, 640 (1980).

${ }^{16}$ P. Bergman, G. Ying, B. Monemar, and P. O. Holtz, J. Appl. Phys. 61, 4589 (1987).

${ }^{17}$ S. Nakamura and G. Fasol, The Blue Laser Diode (Springer, New York, 1997).

${ }^{18}$ F. Mireles and S. E. Ulloa, Phys. Rev. B 58, 3879 (1998).

${ }^{19}$ http://www.phys.ksu.edu/area/GaNgroup

${ }^{20}$ N. Nepal, M. L. Nakarmi, K. B. Nam, J. Y. Lin, and H. X. Jiang, Appl. Phys. Lett. 85, 2271 (2004).

${ }^{21}$ K. B. Nam, J. Li, M. L. Nakarmi, J. Y. Lin, and H. X. Jiang, Appl. Phys. Lett. 82, 1694 (2003).

${ }^{22}$ J. Li, K. B. Nam, M. L. Nakarmi, J. Y. Lin, H. X. Jiang, P. Carrier, and S. H. Wei, Appl. Phys. Lett. 83, 5163 (2003).

${ }^{23}$ M. L. Nakarmi, N. Nepal, C. Ugolini, T. M. Altahtamouni, J. Y. Lin, and H. X. Jiang, Appl. Phys. Lett. 89, 152120 (2006).

${ }^{24}$ K. B. Nam, M. L. Nakarmi, J. Y. Lin, and H. X. Jiang, Appl. Phys. Lett. 86, 222108 (2005).

${ }^{25}$ T. L. Tansley and R. J. Egan, Phys. Rev. B 45, 10942 (1992).

${ }^{26}$ J. R. Haynes, Phys. Rev. Lett. 4, 361 (1960). 